\title{
ALCALDES MAYORES DE MINAS DE LA NUEVA GALICIA EN EL SIGLO XVI: EL CASO DE ZACATECAS
}

\author{
JOSÉ ENCISO CONTRERAS \\ Universidad Autónoma de Zacatecas
}

\section{INTRODUCCIÓN}

En Zacatecas se fundó inicialmente un campamento minero donde nada había, excepto un paraje solariego, al norte de la Nueva España, que servía de eventual refugio a la nación zacateca. ${ }^{1}$ Aceptando este hecho, habrá que revisar luego cuáles fueron los instrumentos económicos y sociales mediante los cuales los españoles buscaron darle estabilidad primero, y permanencia después, a la república ${ }^{2}$ que fundaron en Zacatecas.

La historia de la administración de justicia en Zacatecas comienza a mediados del siglo XVI, cuando, prosiguiendo con sus intenciones colonizadoras y de aprovechamiento de los recursos minerales, los españoles implantaron una vieja institución castellana, la alcaldía mayor. Se incorporó además a la institución una serie de adaptaciones a la circunstancia colonial, y fue instituida en Zacatecas en 1549,3 cuando la Audiencia de la Nueva Galicia -entonces con sede en Compostela- designó a Pedro Mejía Melgarejo, como primer funcionario con tal título.

La historia de la justicia en Zacatecas, durante el siglo XVI incluye la transformación que sufrió la institución de la alcaldía mayor, para llegar a convertirse en el corregimiento de la ciudad de Nuestra Señora de los Zacatecas, en 1580.4

No obstante que la administración de justicia en las colonias españolas constituya uno de los temas clásicos de la Historia del Derecho Indiano, acerca del funcionamiento particular de este sistema judicial aún queda mucho por desentrañar ${ }^{5}$. Las fuentes y textos clásicos con que en ocasiones los historiadores del Derecho suelen abordar este tipo temas, no proporcionan los suficientes elementos como para poder explicar las características y desempeño de las instituciones transplantadas al terreno americano, especialmente cuando se abordan enfoques de historia regional.

Las interrogantes que siguen planteando en nuestros días pueden ser respondidas en el terreno de las fuentes para la historia de cada región colonial de que se trate. En ese sentido va este trabajo en torno a Zacatecas, que de alguna manera se identifica como el caso más representativo entre los reales de minas de la Nueva Galicia. 


\section{ANTECEDENTES CASTELLANOS DE LAS ALCALDÍAS MAYORES Y CORREGIMIENTOS}

En su Política Indiana, don Juan de Solórzano y Pereyra, hace un uso indiscriminado de ambos términos, resaltando solamente que este tipo de funcionarios, en cuyas manos estaba la administración de la justicia en villas y ciudades, eran conocidos en el Perú como corregidores, mientras que en la Nueva España se les conocía generalmente como alcaldes mayores. Adicionalmente hace una material equiparación de sus funciones y les atribuye un marco legal similar. ${ }^{6}$

Don Alfonso García Gallo, es a nuestro juicio, el historiador del Derecho Indiano que mejor ha planteado el problema metodológico que sobreviene al estudio de los alcaldes mayores y de los corregidores en las Indias. ${ }^{7}$

Su conclusión al respecto consiste en revelar la relativa confusión que -tanto en la propia legislación indiana, como en la doctrina clásica- parece envolver a las instituciones de las alcaldías mayores y a los corregimientos en las posesiones coloniales españolas, sin mencionar ya la figura de los gobernadores. La confusión la atribuye a que los juristas y responsables de la gobernación de las Indias, a pesar de tener bien claros en su tiempo los criterios para la designación de una u otra autoridad en cada caso -principios propios del saber jurídico de la época, de la costumbre y de los métodos administrativos en boga-, no se preocuparon por hacer explícitos sus criterios de distinción como para que llegaran a nuestros días con la suficiente claridad.

Tanto alcaldías mayores como corregimientos fueron instituciones de origen castellano que comenzaron a formarse al parejo del proceso de afirmación del poder monárquico iniciado en la península Ibérica tanto con el proceso de reconquista impulsado por Fernando III, como con la continuidad que en la integración de la soberanía real desarrolló su hijo, Alfonso X El Sabio; todo ello a partir del siglo XIII. El nombramiento de justicias en ese tiempo equivalía a la designación de alcaldes que ejercían al mismo tiempo el poder de gobernar, y el de juzgar en nombre del rey.

\section{1. Antecedentes de los alcaldes mayores}

Es precisamente éste último monarca quien en su Espéculo escribió:

«Pero que los reyes no pueden ser en sus castillos, en cada lugar, para hacer esta justicia conviene que se ponga y otro de su mano que la haga; así como alcaldes o jueces u otros, de cual manera quier que sean y aquí es dado juzgar; otrosí, merinos y alguaciles y otras justicias de cual guisa quier que sean que han de cumplir lo que ellos juzgaren», ${ }^{8}$ En la Edad Media, el hacer justicia tenía dos connotaciones: la una correspondiente a la estricta función jurisdiccional, y la otra en el sentido de fụnción gubernativa. 9

Ante el panorama de una España disgregada y en conformación, a la que se sumaban paulatinamente los territorios reconquistados a los moros, surge la necesi- 
dad de la Corona por afirmarse y extender el derecho de juzgar, es decir, el judicio ${ }^{10}$, y el de castigar, el lus puniendi, ${ }^{11}$ hacia aquellos sitios y reinos en donde la presencia del rey no fuera permanente. Esta labor jurisdiccional y de gobernación -por lo tanto política- recaía entonces en los funcionarios que, nombrados por el rey, eran llamados también justicias y ejercían en su nombre ambas funciones: el juzgar y el gobernar, sin más mediaciones.

El término alcalde se deriva del árabe al cadí, que significa textualmente el juez; y el uso del vocablo en España data del siglo XI, precisamente en el mismo sentido, para designar al juez por excelencia. ${ }^{12}$

García Gallo define al justicia, como el «encargado de mantener la paz y el orden, y de hacer cumplir lo determinado en su juicio, o como entonces se dice, de "facer justicia"».

En su empeño por extender y garantizar la judicio real, tanto Fernando III como Alfonso $\mathrm{X}$ delegaron facultades de justicia y gobierno en una sola persona. En su tiempo Fernando nombró un merino mayor para los reinos de León y de Galicia, cuyo precedente tenía una antigüedad que databa desde los tiempos de Alfonso VIII. Alfonso X, a su vez, nombró este tipo de funcionarios para la justicia y gobierno del territorio de Andalucía llamados adelantados mayores, quienes teman la representación personal del rey y debían ser tenidos en los territorios conquistados como la autoridad superior, sólo por debajo de la real persona. El Espéculo disponía además que la impartición de justicia de los adelantados y merinos mayores, fuera asesorada por letrados a quienes se les conoció con el nombre de alcaldes, cuyo número sufrió modificaciones durante los reinados de Enrique IV y de los Reyes Católicos.

$\mathrm{Al}$ igual que los merinos mayores, los adelantados mayores gobernaban y juzgaban, pero existió una relación de jerarquía entre ambos en la cual la preponderancia recaía en manos de los adelantados; los merinos, por su parte sólo ejercían en donde no estaban aquéllos. Esta tradición data de la Baja Edad Media española, y fue paulatinamente reforzada por la monarquía que se transformaba avanzando hacia la Edad Moderna.

En el siglo XIV, en los reinos de Toledo, Jaén, Murcia y Algecira, se nombraban por el rey alcaldes mayores, cuya figura y funciones eran muy similares a las de los alcaldes auxiliares de los adelantados y merinos mayores. Durante el siglo XV, los alcaldes de los adelantamientos y merindades, así como los alcaldes mayores, se designaban en un número de dos por cada ciudad, como fue el caso de Toledo, donde el uno era competente en materia civil y su homólogo, en materia penal. Con ésta institución nos encontramos ante la figura de un juez directamente encargado de la incoación y la resolución de procedimientos judiciales.

La jurisdicción de los alcaldes de adelantamientos se extendía por todo el territorio que tenían delimitado, recorriendo ciudades, lugares y villas; mientras en el caso de los alcaldes mayores, no queda aún bastante claro si ejercían su jurisdicción en todo el reino del que era cabeza la ciudad en que residían, o sólo dentro de los límites de ésta última. Una diferencia importante entre los alcaldes de adelantamientos y 
los alcaldes mayores de las ciudades, consiste en que los primeros eran jueces de alzada, porque conocían en segunda instancia de las causas falladas por los alcaldes de las ciudades y villas -es decir, de los elegidos por los consejos municipales-, mientras que los segundos sólo conocían en primera instancia. ${ }^{13}$

En el siglo XV, tanto Enrique II, como Juan I, ya habían creado la Audiencia Real y las Cortes de Bribiesca, respectivamente. Con ello, se privó a los alcaldes de los adelantamientos de su competencia en segunda instancia, y su jurisdicción se redujo exclusivamente a negocios de primera instancia, sólo ejercida en un radio de una a cinco leguas a la redonda del lugar donde residían. Su competencia quedó equiparada a la de los jueces de los consejos municipales, para posteriormente entrar en contradicción con la institución de los corregidores.

\subsection{Antecedentes castellanos de los corregidores}

La figura del corregidor estaba ya establecida en España hacia el siglo XV.

$\mathrm{Su}$ principal diferencia respecto de los alcaldes de adelantamientos y alcaldes mayores de ciudades y reinos, consistió en que éstos últimos, aunque fueran nombrados directamente por el rey, actuaban a la sombra de una institución superior -que eran los

merinos mayores o los adelantados-, y teman originalmente asignada una amplia jurisdicción que recorrían en ejercicio de su cometido, aunque paulatinamente se fue reduciendo a su mínima expresión, y sólo incorporaban competencias de naturaleza judicial.

De cualquier forma, ya para el siglo $\mathrm{XV}$, los adelantados y merinos mayores eran prácticamente cargos honorarios, sin ninguna función práctica -lo cual hizo que los alcaldes mayores y de adelantamientos adquirieran cierta preponderancia y autonomía-. Como ya se dijo, los alcaldes y alcaldes mayores eran jueces en sentido estricto. Por su parte los corregidores, aunque también eran nombrados por el rey, incorporaban y ejercían atribuciones en materia judicial y en materia gubernativa; si bien sus jurisdicciones territoriales sólo se adscribían al lugar en donde residían. Por esta razón, en los sitios donde estuviese nombrado un corregidor por el rey, no podía ejercer su judicio un alcalde mayor o de adelantamiento.

Una semejanza que se dio entre los corregidores por un lado, y alcaldes mayores y de adelantamiento, por el otro, fue el hecho de que todos pudieron nombrar tenientes que ejercieran justicia en su nombre durante sus ausencias, o en lugares donde no residiese el propio justicia. ${ }^{14}$

\section{ALCALDES MAYORES Y CORREGIDORES EN INDIAS}

El descubrimiento y colonización paulatina de las Indias precisó un transplante de las instituciones jurídicas tradicionales de Castilla a las nuevas posesiones, sin hablar de las instituciones originales que se crearon en las Indias. 
Así, el primer alcalde mayor que se nombró en América fue Francisco Roldán, en la antillana isla de La Isabela, durante el mes de marzo de 1496. El cargo de gobernador se encontraba inicialmente incorporado al de virrey, y con posterioridad fueron designados como tales en las cabezas administrativas de las provincias de las Islas y Tierra Firme, paulatinamente ocupadas por los españoles.

Con frecuencia, la gobernación -referida a asuntos de carácter político y administrativo- se delegaba a tenientes de gobernación que actuaban en nombre del titular; los cuales, con el tiempo adquirieron cierta legitimidad y permanencia. En la primera mitad del siglo XVI, llegaron a nombrarse tenientes de gobernadores en Cuzco, Ancerma, Quimbaya, Cubagua y Cartagena, en el cono sur; mientras que la figura de alcalde mayor ya se encontraba durante este mismo periodo en México y Cuba.

El Consejo de Indias comenzó a utilizar el criterio de suprimir paulatinamente los alcaldes mayores, considerados como superfluos «desde el momento en que se constituyen en las ciudades consejos con alcaldes ordinarios 15 y también corregidores». En consecuencia, pronto dejaron de nombrarse tales funcionarios en Cubagua y Guatemala.

Sin embargo en Nueva España, los nombramientos de alcaldes mayores

aumentaron, promovidos por el virrey Antonio de Mendoza. El rey, por su parte, nombraba directamente alcaldes mayores para Yucatán y Cozumel. Se aprobó también que se designaran en Soconusco, Nicaragua, Honduras, Chiapa, Trinidad y otras partes. 16

A mediados del siglo XVI, el número de alcaldías mayores nombradas directamente por el rey en Ultramar, aumentó considerablemente en Centroamérica y México. Paralelamente, proliferaron en Nueva España las alcaldías designadas por las audiencias. En el Perú, el otro gran virreinato que por esos tiempos existía en territorio americano, no proliferaron las alcaldías mayores, excepción hecha de los Reales de Minas.

En la Nueva Galicia -el reino bajo cuya jurisdicción se encontraban las minas de los Zacatecas-, también se instauró la institución de la alcaldía mayor para estructurar el régimen de impartición de justicia. La propia política sobre desarrollo de la minería del virrey Mendoza, se fundamentó en la creación de distritos mineros gobernados por un alcalde mayor, los cuales eran nombrados por la Audiencia. El otro tipo de justicias nombrados por la audiencia para los pueblos de indios fueron los corregidores.

\section{1. La impartición de justicia en las Indias y en la Nueva Galicia}

García Gallo establece importante diferenciación entre los distintos oficios relacionados con la impartición de justicia, vigentes tanto en Indias como en la metrópoli. Nos habla de los funcionarios genéricamente llamados justicias, los cuales se ocupaban tanto de actividades de gobierno, como de las estrictamente judiciales. En segundo término ubica a los llamados jueces, es decir, los oficiales cuyo cometido se 
reducía a las labores concretas de impartición de justicia. De esta forma incluye en el primer apartado -siguiendo la propuesta de Juan de Ovando-, a los virreyes y gobernadores, y en el segundo a los corregidores, alcaldes mayores, alcaldes ordinarios y alcaldes de hermandad. 17

En el ámbito de los justicias, a nivel provincial destacan los nombramientos

de gobernador y los tenientes de gobernador; y a nivel local, el de corregidor.

Entre los jueces, clasifica también a los tenientes letrados y a los alcaldes mayores.

En el nivel local ubica a los alcaldes ordinarios, nombrados por los consejos municipales de las ciudades y villas.

En referencia a los jueces García Gallo opina:

«Estos distintos jueces, todos supeditados a la Audiencia, poseen idéntica jurisdicción en primera instancia en el lugar donde residen, por lo que en caso de competencia entre ellos, la atrae el juez local (alcalde ordinario) a expensas del provincial, y el juez desplaza al gobernador. Los gobernadores y alcaldes mayores, actúan además como jueces de apelación de los alcaldes ordinarios de su provincia en materia civil hasta cierta cuantía; facultad ésta de que carecen los corregidores. » 18

Por otra parte, esta visión jerárquica de la impartición de justicia en las Indias fue particularmente revelada en su tiempo por el licenciado Pedro Delgado de la Peña, quien había sido consejero de Indias -y posteriormente de Castilla-, en 1544:

«... que se hagan por Audiencias, las necesarias, poniéndolas donde más convenga. Y que por ahora se pongan por las Audiencias alcaldes mayores donde había gobernadores, que conozcan en primera instancia donde estuvieren, y en grado de apelación de los alcaldes ordinarios. ${ }^{19}$

\subsection{La Audiencia de la Nueva Galicia y la impartición de justicia}

El Nuevo Reino de Galicia, dentro del cual se comprendían los territorios de los actuales estados mexicanos de Jalisco, Nayarit, Zacatecas, Aguascalientes, y partes de los estados mexicanos de San Luis Potosí y Guanajuato ${ }^{20}$, fue conquistado por Beltrán Nuño de Guzmán, quien se lanzó a esta empresa entre 1529 y 1530 . Se tiene noticia que tras la conquista, Nuño comenzó a repartir encomiendas y a impulsar la fundación de diversas ciudades y villas como Compostela y Guadalajara, entre 1530 y 1531, Espíritu Santo en 1531 y La Purificación en 1533.21

Siendo gobernador de la Nueva Galicia, Nuño designó, algunos alcaldes mayores, como fue el caso de La Purificación. ${ }^{22}$

Mediante unas ordenanzas dadas por el Consejo de Indias, -fechadas en Alcalá de Henares el 13 de enero y el 13 de marzo de 1548-, se creó la Audiencia de la Nueva Galicia a fin de que los súbditos del reino «y los naturales que pidieran justicia, la alcancen». ${ }^{23}$ En las ordenanzas se asienta la nueva audiencia en la ciudad de Compostela, y se designan como sus integrantes a cuatro Oidores alcaldes mayores, que fueron el licenciado Hernán Martínez de la Marcha, el licenciado Lorenzo 
Lebrón de Quiñones, el doctor Juan Meléndez de Sepúlveda y el licenciado Miguel Ladrón de Contreras y Guevara. ${ }^{24}$

A la nueva audiencia se le dio competencia en asuntos civiles y criminales -así de oficio como a petición de parte-, en grado de apelación, dado que las audiencias eran por excelencia tribunales de alzada respecto de todas las resoluciones emanadas de los alcaldes mayores, corregidores y todo género de jueces ordinarios que ejercieran la jurisdicción de primera instancia en el territorio de la Nueva Galicia. De igual forma, tenían facultad para admitir las apelaciones que fueran interpuestas, en contra de sus propias resoluciones, ante la Audiencia de la Nueva España. Además, los oidores alcaldes mayores podían conocer asuntos en primera instancia que surgieran en un ámbito territorial de doce leguas a la redonda de la sede de la audiencia. Y tratándose de casos de corte. ${ }^{25}$ su competencia se extendía a todo el territorio neogallego en primera instancia, pudiéndose apelar de sus resoluciones ante la Audiencia de México, excluidos los asuntos cuya cuantía fuese menor de trescientos pesos de oro de minas.

Lo mismo ocurría en materia criminal cuando se tratara de casos de privación de la vida, pues las partes podían apelar ante la Audiencia de México, o si había transacción entre ellas, podían solicitar la revista de la causa mediante el recurso de suplicación.

Los oidores quedaban también obligados a realizar visitas por las provincias del reino, así que, por turno, deberían aplicarse «visitando los pueblos y ciudades, villas y lugares» de su jurisdicción, con el propósito de administrar justicia; de tal forma que en todo momento siempre estuviese uno de ellos en visita informándose de los delitos cometidos y «cómo son tratados los naturales de aquella tierra, y si se cumplen y guardan las ordenanzas e instrucciones que para su buen tratamiento están hechas y se hicieren». Concluida la visita, el oidor alcalde mayor debería rendir un informe a la audiencia en donde se proveería lo conducente en materia civil o criminal, fallando el visitador en los negocios que no superaran una cuantía de treinta mil maravedises, pudiendo admitir el recurso de apelación ante la propia audiencia de Compostela. Un similar criterio de alzada quedó establecido para las causas criminales.

La audiencia era también la encargada del gobierno de su territorio y estaba facultada para proveer oficios de corregimientos a la manera en como lo podía hacer la Audiencia Real de los Confines. ${ }^{26}$ De igual forma, los oidores alcaldes mayores quedaban autorizados para traer vara de justicia, 27 a la usanza de los oidores de la Audiencia de México. Además se les autorizó a tomar juicios de residencia a los alcaldes ordinarios y a cualquier otra persona con cargo de administración de justicia en el territorio de su jurisdicción. Finalmente, se les ordenó tomar cuentas a los oficiales reales de la Nueva Galicia. 28

Debe anotarse que el sometimiento de las decisiones judiciales -cuando el derecho así lo prescribía- de la audiencia de Nueva Galicia ante la Audiencia de la Nueva España, se debía a que en su origen, la primera quedaba subalternada ${ }^{29}$ a la segunda, según las ordenanzas de 1548, situación que se modificó posteriormente, en 1572 cuando se le dieron nuevas ordenanzas. ${ }^{30}$ 
En el contenido de las ordenanzas sólo se permite a la audiencia nombrar corregidores en auxilio de su cometido de impartición de justicia, aunque como se vio antes de su implantación ya se habían dado casos en que se nombraran alcaldes mayores para administrar justicia a nivel local o provincial.

En la Nueva Galicia, se instauró un funcionario de justicia intermedio entre los pueblos de españoles o indios y la propia audiencia, nombrados por ésta última. $\mathrm{Al}$ parecer la regla general no escrita, ni siquiera en las ordenanzas de la audiencia, fue la de nombrar alcaldes mayores en las poblaciones de españoles y los reales de minas, y corregidores para los pueblos de indios, en apego a la tradición instaurada en la Nueva España.

Sin embargo, aunque nominalmente había cierta diferencia, lo cierto es que su función en los hechos tenía bastantes similitudes.

\subsection{Corregidores de pueblos de indios y alcaldes mayores en la Nueva Galicia}

Hasta el momento, las atribuciones de los alcaldes mayores y corregidores neogallegos, han sido analizadas partiendo principalmente de los nombramientos realizados por la audiencia; sin embargo, otra importante fuente para su conocimiento son las diversas ordenanzas dictadas para regir a todo el reino o bien para una determinada villa o ciudad.

En 1570, previo a la conversión de la audiencia subordinada de la Nueva Galicia en Real Audiencia y Cancillería, autónoma, el licenciado Contreras y Guevara realizó una amplia investigación sobre el estado del reino en materia gubernativa, política, poblacional y eclesiástica.

En sus averiguaciones Contreras informaba que en todo el reino de la Nueva Galicia vivían un total de 1500 españoles con casa fundada. Cincuenta y cinco de ellos eran encomenderos o detentaban parcialmente una encomienda. El resto se desempeñaban como estancieros, mineros, mercaderes, oficiales y demás ocupaciones. Además se daba cuenta de la existencia de un total de 20.000 indios jefes de familia, pacificados y asentados. ${ }^{31}$

Esta población se repartía entre dos ciudades: Guadalajara y Compostela; cinco villas: La Purificación, San Miguel de Culiacán, Santa María de los Lagos, Nombre de Dios y Jerez de la Frontera; en dieciséis poblaciones de minas: Zacatecas, San Martín, Sombrerete, Las Nieves, Los Ranchos, Chalchihuites, Avino, Santiago de la Espada, El Fresnillo, Mazapil, Xocotlán, Guaxacatlán, Analco, Guachinango, Espíritu Santo y Culiacán. ${ }^{32}$ Además había quince sedes de corregimientos de indios y treinta sedes de tenientes de corregidor.

Aunque J. H. Parry haya escrito que en esta fecha se nombraban anualmente por la audiencia quince alcaldías mayores y cuarenta y cinco corregidores, ${ }^{33}$ de los documentos sólo se desprende que la audiencia expedía títulos anuales a trece alcaldes mayores en las poblaciones mineras y villas de españoles de la jurisdicción de la 
audiencia, de los cuales, cinco ejercían al mismo tiempo el cargo de corregidores en algunos pueblos de indios, generalmente aledaños a las sedes de sus jurisdicciones.

En el citado año de 1570 sólo se nombraban quince corregidores de indios y treinta tenientes de corregidores. La suma de los dos conjuntos fue la que probablemente confundió a Parry.

Los diversos distritos mineros argentíferos de cierta importancia estaban gobernados y bajo la jurisdicción de un alcalde mayor. Una gran parte de ellos fueron nombrados al final de la década de los cuarenta y comienzos de los cincuenta, como lo fueron los casos de Tepeque, Guachinango Xocotlán y Guaxacatlán, Acutlapilco y Zacatecas. Con el tiempo, cuando fueron descubriéndose nuevos yacimientos, se les siguieron nombrando alcaldes mayores.

\subsubsection{Los Corregidores de pueblos de indios y los alcaldes mayores, según los nombramientos de la Audiencia de la Nueva Galicia}

Para examinar las atribuciones de los corregidores de indios, hemos seleccionado el nombramiento como tal de Antonio Maldonado y una minuta que se utilizaba por la audiencia en $1570{ }^{34}$ para la provisión de dichos oficios. Al cargo de corregidor se le mandataba:

a) La jurisdicción civil y criminal del pueblo y sus sujetos.

b) La visita de la jurisdicción del pueblo, en busca de posibles despojos injustos de las tierras de los indios, y en caso de que encontraran esos casos, tenía el deber de obligar al despojante a la restitución de las tierras; en caso de no poder efectuar tal restitución, el corregidor estaba obligado a rendir un informe a la audiencia para que en ella se resolviera lo conducente.

e) Se le encargaba procurar la evangelización de los indios de sus pueblos.

d) Se le cometía que averiguase si había hijos de españoles entre las indias de los pueblos a fin de que les fueran entregados a sus padres.

e) En los casos de pleitos o delitos en que se vieran involucrados los indios caciques y gobernadores, el corregidor quedaba impedido para dictar sentencia. Sólo se le ordenaba la instrucción del sumario y el envío de los autos a la audiencia para su resolución definitiva.

f) Se le impedía dictar sentencia en aquellos procedimientos cuyas penas fuesen la capital o de mutilación de miembros. En tales situaciones, hecha la información del sumario, debía remitirla a la audiencia para que allí fuese fallada la causa.

g) Se le encargaba que todos los víveres que los viajeros de paso por el corregimiento tomaran a los indios, les fuesen pagados a estos últimos a precios justos y moderados. 
h) Además se le ordenaba impidiera que los indios del corregimiento fueran cargados como tamemes, ${ }^{35}$ aun cuando y ellos mismos consintieran hacerlo. Asimismo debía impedir que los indios fueran utilizados en la construcción de monasterios y otras obras sin la expresa licencia de la audiencia.

i) Se le prevenía para que impidiera que ninguna persona, así españoles como indios, portara vara de justicia en su jurisdicción, sin expresa licencia real o de la audiencia. Debía confiscarse la vara al infractor, prenderlo, hacer el sumario y enviar a ambos a la audiencia para que allí se resolviera.

j) Se le ordenaba la persecución de los españoles que fueran casados en la Península -con sus mujeres vivas en ella-, quedando facultados para aprehanderlos, confiscar sus bienes y enviarlos a la audiencia para que finalmente fueran remitidos a la metrópoli. Lo mismo se ordenaba en el caso de los extranjeros vetados para vivir en las Indias.

k) Se le atribuía competencia en materia de bienes de difuntos, debiendo practicar las diligencias de inventarios y almonedas, remitiendo todo al juez de bienes de difuntos de la audiencia, para su envío a España.

1) Se le prohibía cobrar y recibir dinero por concepto de pago de tributos en los pueblos de su jurisdicción, so pena de la destitución del oficio y de cien pesos de multa.

m) Se le encargaba mantuviera la población indígená ocupada en sus labores agrícolas y en las del rey, así como en la crianza de gallinas. Para lo cual se nombraría un buen indio lugareño que vigilase el cumplimiento de tales actividades, al cual se le concedería vara de justicia. También se encomendaba al corregidor fiscalizar las cuentas de la caja de la comunidad.

n) Se le ordenaba permanecer en la cabecera del corregimiento por lo menos la tercera parte del año para el que había sido nombrado, so pena de haber perdido su salario.

Por otra parte, las funciones que legalmente confería la Audiencia de la Nueva Galicia a los alcaldes mayores designados por ella para la impartición de justicia en los pueblos de españoles y en los reales de minas, pueden verse en los propios nombramientos que expedía.

Para el caso de Zacatecas, hemos elegido el nombramiento de uno de sus alcaldes mayores, nuevamente de Antonio Maldonado, expedido en Compostela en 20 de mayo de 1560 por los Oidores alcaldes mayores: el licenciado Alonso de Oseguera y el doctor Morones. El nombramiento de Maldonado lo era al mismo tiempo como corregidor del pueblo de Mezquituta, ${ }^{36}$ lo cual nos permitirá hacer una somera extrapolación de las similitudes y diferencias de uno u otro oficio. Además hemos revisado el nombramiento de Pedro de Ledesma, como alcalde mayor, dado por la audiencia el 13 de octubre de 1563. Y, finalmente, el nombramiento del licenciado Rodrigo Sánchez, emitido por el citado tribunal el 15 de diciembre de 1574. ${ }^{37}$ 
Las atribuciones delegadas en ambos nombramientos de alcalde mayor de las minas de Zacatecas, eran las siguientes:

a) La impartición de la justicia de primera instancia en materia civil y criminal, en el distrito de las minas. «Conociendo, librando y determinando todos los pleitos y causas. »

b) La tutela del orden público -«paz y sosiego»- de los moradores del distrito.

c) La conservación y bien de los naturales del reino, y en particular de los avecindados en la jurisdicción de las minas, haciendo cumplir las ordenanzas que sobre el buen tratamiento y preservación de los indios estuvieran dadas o se decretaran en lo sucesivo.

d) Se le asignaba, en algunos casos, el título de justicia y alcalde mayor, con la facultad de portar vara de justicia.

e) Se le encomendaba la evangelización de los indios que vivieran en su distrito.

f) Se le cometía la averiguación de la existencia de hijos que los españoles hubieran procreado con las indias de su jurisdicción, para que fueran entregados a sus respectivos padres.

g) Se le ordenaba vigilar que ninguna persona, ni español ni indio, portara vara de justicia en la jurisdicción, sin expresa licencia real. En tales casos debían confiscar tal vara, prender a los infractores y una vez hecho el sumario, enviarlo a la audiencia para su resolución.

h) Se le nombraba depositario de las penas de cámara a que el mismo alcalde condenara a los infractores de la ley, y quedaba obligado a dar cuenta de los fondos cada vez que le fuera solicitada.

i) Se le proporcionaba competencia para conocer en materia de bienes de difuntos Presidiendo personalmente la elaboración de inventarios y almonedas, dando de todo ello parte al juez de bienes de difuntos de la audiencia.

j) Se le ordenaba nombrar dos intérpretes de confianza en las causas donde se vieran involucrados indios.

k) Se le confiaba la persecución de los españoles que, siendo casados en la península, no vivieran con sus mujeres en la Nueva Galicia. En estos casos debían igualmente prenderlos y confiscar sus bienes para que, una vez remitido todo lo actuado a la audiencia, fueran enviados de vuelta a la metrópoli. Se les determinaba la misma obligación respecto a los extranjeros de los reinos de Castilla, cuya presencia en las colonias estuviera vetada por la ley.

\subsubsection{Diferencias y similitudes entre ambos cargos, según los nombramientos de la audiencia}

Del análisis de los documentos mencionados, es posible sacar algunas conclusiones. 
En principio que ambas instituciones, las alcaldías mayores y los corregimientos de indios en Nueva Galicia, cumplían ante todo una función judicial de primera instancia, ejerciendo la jurisdicción mixta, penal y civil que, como ya vimos, deviene de una ancestral tradición bajomedieval española.

Por otra parte, ambos oficios eran designados por la audiencia a efectos de que en su representación, impartieran la justicia del rey en primera instancia, en los distritos a que eran destinados. Quedando demarcadas además sus competencias en aquellos pleitos y causas que, bien por la cuantía o por la naturaleza de las penas a imponer, fueran consideradas como arduas. 38

Por otra parte, las sentencias de corregidores de indios y de alcaldes mayores, según las ordenanzas de la audiencia neogallega de 1548, eran recurribles en apelación ante el propio tribunal que tuvo su sede definitiva en la ciudad de Guadalajara.

Sin embargo, una diferencia sustancial entre ambas instituciones, respecto a los oficios precursores castellanos es que incorporaban indistintamente atribuciones de gobernación, en lo general. Con esto nos referimos a que más allá de ser ubicados en el estricto concepto de jueces, ejercían la otra labor aparejada a la justicia conocida como gobernación. Si según las ordenanzas de 1548, la audiencia quedaba investida con la facultad del gobierno de la Nueva Galicia, también se le autorizaba para delegar esta función en los corregidores y por extensión en los alcaldes mayores. De allí que ambos oficios, a su manera -y con la especialidad ya citada de ejercer el oficio en pueblos de españoles o de indios, respectivamente-, también fueran los titulares del gobierno de las jurisdicciones en donde residían.

Es en la propia materia de este conjunto de facultades gubernativas peculiares a ambos oficios, donde se pueden encontrar las diferencias entre ellos. El corregidor era la máxima autoridad gubernativa y judicial de un pueblo de indios, por lo que se le encargaba el cumplimiento de la legalidad que en materia de evangelización y conservación de los naturales, dimanaba de la legislación indiana. El mismo cometido era dado en lo general para los alcaldes mayores, pero tratándose de corregidores sus obligaciones eran más explícitas; tanto en lo relativo a cuidar el orden público entre los indios como en lo tocante a velar por su permanente ocupación, y protección, así como por la restitución de las tierras que injustamente les hubiesen sido despojadas.

Un ejemplo típico de las atribuciones gubernativas del corregidor lo encontramos en su facultad para auxiliarse de un teniente indio, encargado de vigilar el cumplimiento de lo dispuesto en materia de actividades agrícolas y de crianza avícola. Por lo demás el corregidor tenía la facultad de pedir cuentas a los indios encargados de la administración de la caja de la comunidad.

Según los nombramientos expedidos por la audiencia, las tareas gubernativas que se encargaban específicamente a los alcaldes mayores y eran muy similares a las de los corregidores, si bien menos extensas. Estos alcaldes eran responsables de la tutela del orden público; se les daban indicaciones para el cuidado y preservación de los indios y se les nombraba como depositarios de las penas de cámara a que condenaran en el ejercicio de sus funciones. Eventualmente cumplían funciones de guerra y 
protectorado, como fue en el caso del alcalde mayor del Mazapil, a quien se le confería además la responsabilidad de «capitán a guerra y protector de los indios guachichiles. »

Igualmente entendían de negocios en materia de bienes de difuntos y de expulsión de extranjeros y españoles indeseables del distrito de su jurisdicción, y quedaban además obligados a asistirse por dos intérpretes confiables de las diversas lenguas autóctonas, en los casos de que en las causas que incoaran se vieran involucrados indios.

Otra diferencia que puede anotarse entre ambos funcionarios es la regla general aplicada para la obtención de los salarios. En el caso de los corregidores, su salario se obtenía de los tributos que los indios de la jurisdicción respectiva pagaban, mientras que los alcaldes mayores lo obtenían a su vez de los gastos de justicia, es decir, de las penas de cámara o multas que ellos mismos aplicaran.

Vale la pena anotar aquí que aunque los nombramientos contuvieran una enumeración formal de atribuciones, en los hechos el ejercicio de las funciones reales de estos justicias rebasaba con mucho el contexto de los documentos. No siempre en el sentido de que estas prácticas fueran de carácter ilegal, sino muchas veces sustentadas en la legislación indiana que les reconocía en muchos casos facultades adicionales y con frecuencia mayores grados de especialización, como en el caso de los alcaldes mayores de minas, que veremos adelante. Por otra parte era muy frecuente que ambos cargos recayeran en un mismo individuo, quien personalmente o mediante un teniente, impartía justicia en una y otras jurisdicciones. A lo anterior debe agregarse lo que ya se insinuaba líneas arriba: que un gran número de prerrogativas de los alcaldes mayores se fueron generando en las diversas ordenanzas provinciales o locales que se redactaron con alguna frecuencia durante el siglo XVI. Esto se explica en parte por una característica intrínseca que acompaña la esencia de una normatividad de tipo medieval y en transición a lo moderno como lo fue el derecho indiano; nos referimos a la casuística, como concepto opuesto al de sistema jurídico. Ella consiste en que las características propias de la materia o del sitio en que debía aplicarse una determinada disposición, determinaban en un alto grado los rasgos propios de la propia disposición. En síntesis: una respuesta jurídica para cada problema jurídico.

\section{LA ALCALDÍA MAYOR DE MINAS DE ZACATECAS}

El 29 de diciembre de 1548 en Guadalajara, un grupo de españoles integrado por el cabildo de esa misma ciudad, por procuradores de la villa de La Purificación y de los mineros de Zacatecas, formularon al recién llegado oidor alcalde mayor de la Nueva Galicia, el licenciado Lorenzo Lebrón de Quiñones, la petición de que la nueva audiencia no se asentara en la ciudad de Compostela sino en Guadalajara. Después de exponer su petición, el procurador de los mineros de Zacatecas, a la sazón don Juan de Zaldívar, expuso la problemática existente en las recientemente descubiertas minas. Explicó entonces la urgencia de que la audiencia designara un 
alcalde mayor en Zacatecas -donde no lo había- debido al caos y clima de violencia imperante.

« ... como es mandar vuestra merced elegir alcalde mayor en las minas de los Zacatecas, a lo menos hasta tanto que el audiencia se junta y provee justicia en ellas, porque a causa de ser nuevamente descubiertas, no hay en ellas justicia al presente; y hay en ello muchos molestados; y que a causa de no haber justicia pierden su derecho y hacienda; y hay entre ellos debates y pendencias de que se podrían recrecer muertes de hombres y otros grandes daños. $\gg^{39}$

Se quejó de la desprotección que sufrían los indios de la comarca con el gran tráfico de personas que se dirigían a Zacatecas en busca de fortuna. Expuso también la necesidad de que se dictaran urgentes medidas para garantizar el abasto de bienes de consumo a las nuevas minas. En consecuencia, al año siguiente la audiencia de la Nueva Galicia designó al primer alcalde mayor de las minas de los Zacatecas, cuyo nombramiento recayó en Pedro Mejía.40

De allí en adelante hasta 1580 , la justicia y el gobierno del distrito minero recaería en un alcalde mayor; cargo para el que, aunque la naturaleza del oficio sugiera otra cosa, de 1549 a 1580 se nombraron escasos profesionales versados en asuntos de jurisprudencia, como fueron los casos del licenciado Sotomayor, en 1574 y del licenciado Rodrigo Sánchez, en 1575; el resto, en su mayoría fueron hombres de capa y espada.

Tras la conquista de los territorios americanos, el desempeño de cargos de cierta importancia era reservado especialmente para aquellos españoles que pertenecían al grupo social de elite que nació a partir de la conquista, y que fue conocido como los beneméritos. Con la paulatina conquista y pacificación de la Nueva Galicia fueron considerados como así, en un principio, los conquistadores que habían participado directamente en las batallas de conquista y pacificación, así como sus descendientes. Se integraban además a este grupo los llamados primeros pobladores y también sus descendientes. A ellos les fueron concedidas, a manera de botín, los elementos que simbolizaban tanto la riqueza como la nobleza y la preeminencia. La tierra, las encomiendas de indios y los algunos cargos reales.

El principal grupo de beneméritos de la Nueva Galicia se estableció en la ciudad de Guadalajara y encontraron su representación política en el cabildo. Pero además, merced a las Leyes de Indias, ellos tenían prelación al momento de que las audiencias y autoridades coloniales repartían oficios y puestos administrativos. Por ahorro de espacio en este trabajo, sólo nos asomaremos a los datos biográficos de algunos de ellos que fueron designados como alcaldes mayores de Zacatecas.

Dentro del grupo de los conquistadores beneméritos que fueron nombrados como alcaldes mayores de las minas de los Zacatecas, destaca Francisco Delgadillo, quien se desempeñó en el año de 1573. Era originario del Valle de santo Domingo, en Toledo.41 Fue conquistador de la Nueva Galicia con Nuño de Guzmán en 1529, habiendo llegado a la Nueva España con posterioridad a la caída de Tenochtitlan; participó activamente en las diversas defensas de la tercera ciudad de Guadalajara, y se 
le considera como uno de los fundadores de la definitiva capital de la Nueva Galicia en 1542. Fue encomendero en Apozol -en el actual municipio del Estado de Zacatecas- y en Atiztaque, en Tonalá. Ambos pueblos seguían a su nombre hacia 1550. Seguía al parecer vivo en 1592 y su viuda, Isabel de Ávalos Sandoval, obtuvo una merced del virrey consistente en un sitio de ganado mayor entre Zacoalco y Acatlán. ${ }^{42}$ Siempre fue vecino de la ciudad de Guadalajara, de cuyo cabildo fue miembro; en 1550 era alcalde ordinario. Incursionó en empresas mineras en Taxco y Zultepec y llegó a tener haciendas de minas en Zacatecas, las cuales vendió, según declaró aquí mismo hacia 1561, por resultar las haciendas demasiado onerosas. ${ }^{43}$

Otro de los beneméritos conquistadores de que tengamos noticia haya sido alcalde mayor de Zacatecas, entre los años de 1554 y $1555^{44}$ fue Gaspar de Tapia, quien era castellano de origen y se encontraba entre las huestes de Cristóbal de Oñate; es muy probable que haya participado en el sofocamiento de la rebelión del cerro del Mixtón ${ }^{45}$ y había sido minero en Xocotlán. Se tiene constancia de su carácter pendenciero y problemático, pues los oficiales de la real hacienda en Zacatecas, se quejaron ante el rey en septiembre de 1555, de haber impedido con violencia el traslado de la caja real a Guadalajara. ${ }^{46}$ Amaya Topete lo tacha de pendenciero e inquieto. Fue también alcalde mayor de las Minas de San Martín, en el actual Sombrerete, en 1572 o poco antes. 47

Un benemérito y antiguo poblador de la Nueva Galicia fue Juan de Rentería, quien por su parte se desempeñó como alcalde mayor de Zacatecas en varias ocasiones, en 1564, 1565, 1566 y 1570, según las constancias documentales. ${ }^{48}$ Era de origen extremeño, oriundo del Valle de Vaquío, en Plasencia. Llegó a poseer una estancia en el valle de Ameca, dedicándola a la agricultura y a la ganadería. Fue además alcalde mayor de Pátzcuaro y de las provincias de Ávalos.49

Pedro de Ledesma fue alcalde mayor de Zacatecas en 1563 y tuvo algunos homónimos contemporáneos. Sin embargo, acerca de él en lo particular existe importante información, que ha sido recopilada en su mayor parte en fechas recientes. Sabemos que era oriundo de Madrid e hijo de un Juan de Ledesma. Es bastante probable que haya llegado a la Nueva España en 1537, y ciertamente participó en la pacificación del norte de Nueva Galicia; posteriormente intentó negocios en las minas de Zacatecas. Aparentemente Ledesma se mudó de la Nueva Galicia con posterioridad a ejercer como justicia en Zacatecas. En torno a 1555 casó con doña Catalina Ortiz, criada de doña Ana de Castilla, esposa del virrey don Luis de Velasco. Hacia 1580 se desempeñaba como alcalde mayor de las minas de Taxco. Se le tenía como hombre activo y burócrata leal. Llegó a proponer proyectos al rey para el beneficio del añil en 1584. Tras la implantación de la Inquisición, fue familiar del Santo Oficio.50

La regla general indica que para los pueblos de españoles eran designados alcaldes mayores, en los reales de minas también fueron designados la misma clase de funcionarios, con la particularidad de que su jurisdicción era ampliada a conocer de asuntos en materia minera, de tal suerte que en términos jurídicos eran alcaldes mayores de Minas. 


\section{1. Los alcaldes mayores de minas según las Leyes de Indias}

Dada la naturaleza del asentamiento poblacional que surgió con motivo del descubrimiento de los yacimientos de plata en Zacatecas, puede afirmarse que el alcal. de mayor que comenzó a designarse por la audiencia estaba investido de competencia en materia minera.

Los alcaldes mayores de minas fueron jueces con algún grado de especialización y particular objeto de regulación del Derecho Indiano.51 Sin embargo, la propia Recopilación de 1680 es más bien parca al momento de establecer un perfil jurídico de la institución; huelga decir que estos cargos eran nombrados para ejercer como justicias en los distritos mineros de las Indias. Básicamente tenían competencia para conocer de pleitos suscitados con motivo del descubrimiento, propiedad y registro de minas.

Las Leyes de Indias recomendaban que quienes se designaran para estos puestos tuvieran la suficiente experiencia en materia minera, ${ }^{52}$ y establecieron además una serie de prohibiciones para mantener la deseada imparcialidad en la justicia minera, tales como el ejercicio del comercio de metales y el que por sí mismos o por interpósitas personas se dedicaran a la minería. 53

Las mismas leyes prescribían que los salarios de los alcaldes mayores de minas fueran obtenidos de los aprovechamientos y ganancias de las minas que tuviera bajo su jurisdicción, y no de la real hacienda..$^{54}$

\subsection{Sus atribuciones respecto de la Diputación de las Minas}

La diputación de minas de Zacatecas fue una institución capitular, 55 de naturaleza paramunicipal. El máximo organismo para sus decisiones internas lo constituyó su cabildo, integrado al momento de su creación por cuatro diputados e incluyendo al alcalde mayor. No conocemos las circunstancias concretas que se presentaron en su integración original en 1553 , pero sí que este colegiado de cinco miembros sufrió posteriormente algunas modificaciones en lo que toca al número y calidad de sus integrantes. En épocas tardías, desde 1577 y 1581, se integraron en su seno los oficiales reales como regidores permanentes; y hacia 1582 un alguacil mayor también se había incorporado. ${ }^{56}$ En 1580, cuando la jurisdicción de las minas de Zacatecas se transformó de alcaldía mayor en corregimiento, 57 el corregidor se integró permanentemente en el cabildo desempeñando el mismo papel que sus predecesores.

Los alcaldes mayores de las minas de Zacatecas, cuando no la subordinaron totalmente, compartieron responsabilidades con la diputación que existió hasta antes de que se instaurara el cabildo municipal en 1587.58 De entre las funciones que ejercieron los justicias en la diputación destaca la de presidir las sesiones ordinarias y las electivas de diputados cadañeros. Si bien la carencia de alcaldes ordinarios caracterizó a la diputación, la subordinación de esta última a la autoridad de los alcaldes mayores -y después a la de los corregidores, así como a la influencia de la audiencia-, fue también una constante en la historia de aquella institución capitular. 
Los alcaldes mayores ejercieron además un considerable número de facultades, y dependiendo de la personalidad de los justicias involucraban al cabildo en sus particulares decisiones, asentando en el respectivo libro de la diputación esta mancomunidad de responsabilidades. Fuera de lo anterior, los nombramientos para cargos que típicamente le eran propios al alcalde mayor, algunas veces se anotaron en el libro, como fueron los de alguacil de campo -que se encargaban de la persecución de los delitos y pecados públicos y de los negros e indios prófugos de las minas; así como de la conservación de los montes y vigilancia de los caminos- y los de intérprete del juzgado. 59

El alcalde mayor era una autoridad independiente que podía actuar al margen y con plena autonomía del cabildo. Los asuntos relativos a la estricta justicia en materia minera jamás formaron parte del conjunto de las actividades que el alcalde mayor o el corregidor tuvieran o compartieran con el cabildo de la diputación.

Por otra parte, es muy probable que la cala y cata de algunos productos de consumo básico en las minas, como el maíz, estuvieran siempre reguladas desde la instauración del alcalde mayor. No obstante, algunas veces el justicia de turno, invitó a los diputados a participar directamente en esa responsabilidad, como se dio, por ejemplo, en 1575.60

Al principio los diputados podían regular el abasto de la carne en Zacatecas, así como designar funcionarios que vigilaran el mercadeo del producto con fidelidad a los precios impuestos y conforme a pesas exactas. Finalmente, esta mínima función -originalmente compartida con el alcalde mayor- fue separada del conjunto de las facultades de la diputación, ya que también en 1575 elegía por vez primera, junto con el alcalde mayor, al fiel y veedor de las camicerías. ${ }^{61}$ Por otra parte, justicia y diputados en su ayuntamiento, en ocasiones se vieron movidos a prevenir la especulación de bienes de consumo, conducta frecuente en las minas que se acentuaba en tiempos de crisis. ${ }^{62}$

Por otra parte, los diputados y el alcalde mayor realizaron actos de administración de los bienes de propios que efectivamente existieron, pues en abril de 1575, como ya se apuntó, decidieron arrendar las estancias de ganado que pertenecían explícitamente a la institución; y en septiembre del año siguiente la justicia y los diputados resolvieron sobre la venta del edificio de la cárcel con el propósito de comprar otro solar donde construir una nueva. ${ }^{63}$

\subsection{Sus atribuciones en materia minera}

Si bien las Leyes de Indias no nos proporcionan elementos suficientes como para entender la complejidad institucional de los alcaldes mayores de minas, algunas ordenanzas, dadas por las autoridades indianas para tener vigencia a nivel provincial, pueden proporcionamos una nítida imagen de ellos.

Sobre nuestro objeto de estudio las ordenanzas de carácter provincial hechas en Zacatecas, para ser aplicadas «en este Nuevo Reino de Galicia», dadas por el licen- 
ciado Hernán Martínez de la Marcha, ${ }^{64}$ el 20 de abril de 1550 -durante la primera visita que se realizó a esta parte de la Nueva Galicia-, serán de suma utilidad al momento de explicar las facultades que en materia minera tuvo el alcalde mayor y el corregidor de Zacatecas. ${ }^{5}$ Demetrio Ramos ha estudiado el paulatino proceso de regulación provincial de las actividades mineras durante el siglo XVI en las colonias españolas, descubriendo extremos regionalistas y características casuistas, en las diferentes y múltiples ordenanzas de alcance provincial y hasta local.66

El hecho de que las ordenanzas en cuestión fueran efectivamente vigentes para Zacatecas lo deducimos de la parte final de las ordenanzas en que el oidor mandó que todos los alcaldes mayores $\mathrm{u}$ otros justicias de todas las minas de la Nueva Galicia las cumplieran y ejecutaran. $\mathrm{Y}$ añadió que esas normas fueran pregonadas en las minas de Zacatecas y en las demás del reino. Están datadas en las minas de Zacatecas el domingo veinte de abril de mil quinientos cincuenta, y fueron pregonadas ese mismo día. A más de lo anterior, las atribuciones mineras de los justicias no sólo se encuentran en las ordenanzas de alcance provincial, como lo son las del oidor la Marcha y otras, ${ }^{67}$ pues existieron también varios cuerpos normativos redactados por alcaldes mayores cuya vigencia fue estrictamente local y sobre temas diversos conectados con las actividades extractivas. Pueden citarse en ese sentido las ordenanzas para la cosecha y repartimiento de la sal, dadas por la diputación de minas, junto con el alcalde mayor, Pedro de Ledesma, el 15 de diciembre de 1562.68

Sin embargo, la intención fundamental que parece inspirar el origen de las ordenanzas de la Marcha en Zacatecas fue la de regular la actividad extractiva de la plata en Nueva Galicia, definiendo claramente las características de la propiedad minera, regulando todos los problemas jurídicos y económicos que pudieran derivarse de ella. Percibiéndose además que se hacía necesario unificar los criterios para el establecimiento de una jurisdicción especializada sobre la materia. En otros términos, los alcaldes mayores designados por la Audiencia de la Nueva Galicia, en los distritos mineros del reino, debían actuar en lo relativo a la resolución de controversias entre mineros bajo reglas claras y uniformes

Las ordenanzas de Hernán Martínez de la Marcha se insertaron en el proceso de imposición de la autoridad real en la Nueva Galicia. Para ello, los funcionarios claves que quedaron investidos con facultades incuestionables de gobierno y justicia fueron los alcaldes mayores de los distritos mineros, que serían los gestores de la política de minería en el reino, tal y como lo harían sus colegas de la Nueva España.

Paralelamente a la competencia en asuntos mineros que de manera general se asignaba a los alcaldes mayores de minas, las ordenanzas establecieron la prohibición de que tales justicias tomaran mina para sí, o en compañía, bajo ningún título ni vía, en la jurisdicción que tuvieran a su cargo, «so pena que la haya perdido y sea del que lo denunciare.» 


\subsection{Registro y regularización de la propiedad minera}

En cada una de las poblaciones mineras, debía existir un libro en el que se asentarían los registros de las vetas que hubiese en la jurisdicción. En ese libro se organizaría un índice alfabético de los titulares de los registros en él contenidos; el volumen se conservaba en el arca de las tres llaves a cargo de los oficiales reales y del alcalde mayor, de donde no debía extraerse sino por causa de eventual litigio. En estos casos, citadas por el juez las partes involucradas y el escribano ante quien se hubiese realizado la inscripción, se exhibiría el registro original en limpio y sin enmiendas, a fin de solucionar el conflicto sobre propiedad.

Se dispuso además que todas las personas que tuvieran minas en la Nueva Galicia, comparecieran ante los alcaldes mayores o demás justicias de la jurisdicción a presentar los registros y títulos que ampararan los derechos sobre sus vetas. En caso de que los interesados no tuviesen registradas debidamente sus minas debían de subsanar su situación efectuando, dentro de los tres meses siguientes a partir de la fecha de publicadas las ordenanzas, el respectivo registro, en el cual debía de asentarse el cerro donde estuviera la mina en cuestión; las pertenencias o colindancias de la mina, mencionando la correspondencia de linderos con otros mineros colindantes, es decir enunciando las estacas 69 «a donde pertenecían»; un juramento sobre la veracidad de los datos contenidos en el registro y la firma y nombre del minero registrante, así como del juez y del escribano ante quien se verificaba el acto.

La inobservancia de estos requisitos acarreaba como consecuencia que «la mina que no estuviere registrada como dicho es, cualquiera persona o personas se la pueda tomar por despoblada y la justicia le dé posesión de ella, aunque la tenga comprada o por cualquier otro título...»70

Las ordenanzas imponían a los dueños de minas despobladas -registradas o no; y a los que en lo futuro registraran-, la obligación de ahondarlas en tres estados, ${ }^{71}$ en el plazo de un año, contado a partir de que las ordenanzas fueran publicadas. De no cumplir esta condición, el infractor perdería la su mina y el alcalde mayor tenía facultades para asignarla a quien la solicitara, acto que se llevaría a cabo aunque el afectado lo apelara.

La pérdida de la propiedad minera por causa de abandono o despoblación, estaba sujeta a un procedimiento dispositivo del que debía conocer el alcalde mayor: En primer lugar, el interesado en ocupar la mina despoblada, debía formular un pedimento ante el juez competente, manifestando en él su intención de labrarla, debiendo expresar en él «clara y abiertamente» la ubicación de la mina, incluyendo el nombre del cerro donde estuviera, así como las estacas que referenciaran su posición, el estado en que se encontraba y si tenía o no tenía metales; luego de formulado el pedimento, el alcalde mayor de las minas debía hacer pregonar públicamente la solicitud, señalando al interesado "para querer tomar y labrar». Dicho pregón debía realizarse en cuatro domingos sucesivos a la puerta de la iglesia principal de las minas o, en su caso, de la del pueblo más cercano «donde se juntan los mineros», precisamente en 
el momento en que estuviera saliendo la gente de misa. Ante el pregonero debían estar presentes cuando menos ocho españoles. Una vez efectuado el pregón, se fijaría un traslado de él en la puerta principal de la iglesia, asentándose al calce la fe de cada una de las cuatro publicaciones dispuestas por las ordenanzas, «para que venga a noticia de todos». Los cuatro pregones sucesivos equivalían a una notificación personal y directa al dueño de la mina solicitada. El pedimento y publicación descritos arriba, debían realizarse con posterioridad a la publicación de las ordenanzas en los diversos distritos mineros. Si durante el plazo de los cuatro pregones, el dueño de la mina denunciada -o persona que la tuviere a su cargo-, llegara a comparecer ante el alcalde mayor y el escribano de las minas para contradecir la «manifestación» del peticionario y reclamar su propiedad, entonces, «constando estar registradas y ahondadas como se contiene en las dichas ordenanzas susodeclaradas», se invalidaría la petición y se respetaría la propiedad de la mina. En contrapartida, si el contradictor no demostrara ante el alcalde mayor reunir cualquiera de las condiciones legales del registro y la profundidad exigida de la cata principal, se le daría posesión inmediata al peticionario, sin que al contradictor se le concediera recurso alguno en contra de tal resolución.

Si nadie compareciera al llamado de los pregones del pedimento, el justicia podía dar licencia «al que manifestó la tal mina para que entre a labrar y sacar metal de ella». La condición para el otorgamiento de la licencia era que el peticionario debía ahondar la cata principal de la mina -en un plazo de tres meses siguientes a la concesión-, en tres estados más de lo que tenía al momento de concedérsela. Si durante ese plazo se presentara ante el alcalde mayor el dueño de la mina, se le reconocería la propiedad pero se tendría al peticionario como su socio. Este hecho no liberaba al peticionario de su obligación de ahondar la cata principal en tres estados, de tal suerte que si no lo conseguía en el plazo establecido, la mina retornaría plenamente a la propiedad exclusiva del dueño que se había presentado en forma superveniente.

Para dar posesión material de la mina al peticionario actuarían un alguacil, un escribano y dos testigos. En la misma diligencia se medirían los estados de profundidad de la cata principal. Por otra parte si el peticionario prefería trabajar en otra parte distinta a la original cata principal de la mina, podía hacerlo con la condición de ahondar la nueva cata en tres estados más otro tanto de la profundidad que tenía la principal, dentro de los tres meses siguientes a que se le permitiera el laboreo. Transcurridos los tres meses, el peticionario quedaba obligado a presentarse ante el alcalde mayor y el escribano de las minas, dándoles aviso del cumplimiento de la condición impuesta para la concesión de la licencia de laboreo. Teniendo el juez constancia del cumplimiento, procedería a darle posesión de la mina al peticionario, quien podía desde ese momento registrarla «como, cosa suya propia». Cuando el peticionario no cumplía las condiciones de la licencia, el alcalde mayor le ordenaría dejar la mina, e incluso le impondría una sanción en caso de renuencia; además perdería cualquier derecho sobre tal mina en lo sucesivo. El juez quedaba obligado entonces a conceder similar licencia a cualquier otra persona que volviera a denun- 
ciar la mina como abandonada, quien a su vez debería cumplir las obligaciones del procedimiento descrito. 72

La Marcha ordenó también que para pedir por despoblada una mina era preciso que el solicitante no tuviera mina en ese momento ni la hubiera tenido en ese distrito minero; en ambos casos se impedía al interesado el ejercicio de ese derecho. De igual forma la ordenanza XLV estableció que sólo podían pedirse por despobladas las minas que hubiesen sido tomadas, pero no las adquiridas mediante compra-venta.

\subsection{Atribuciones del alcalde mayor en materia de descubrimiento y creación del distrito minero}

En las ordenanzas se estableció un procedimiento para regular los descubrimientos y tomas de minas en los que los alcaldes mayores de minas jugaron igualmente un papel preponderante, incrementando el número de sus facultades.

El procedimiento planteaba que de tenía como Primero Descubridor a quien encontrara metal de oro o de plata en un sitio a partir del cual, en mil varas a la redonda 73 no hubiese una sola mina con metales descubierta con anterioridad. En congruencia con la ley de Carlos I, recogida en la Recopilación, ${ }^{74}$ el hallazgo debía ser registrado -mediante las formalidades indicadas arriba- en un plazo de 15 días posteriores a la fecha de su descubrimiento ante los oficiales reales o ante el alcalde mayor más cercano, y dentro de cuya jurisdicción estuviera ubicado. Si fueran dos las personas que hicieran el primer descubrimiento, sería Primero Descubridor, aquel que acudiese en primer término a registrarlo ante el alcalde mayor -sin importar que el otro hubiese encontrado antes el metal en los hechos-, con la condición de que no estacara sobre la veta del otro descubridor, ni a menos de cinco varas de distancia.

\subsection{Atribuciones del alcalde mayor en materia de deslinde y estacamiento de las vetas}

Otra de las operaciones en materia de minas que quedaba a cargo del alcalde mayor, era la del deslinde de la propiedad de los fundos mineros, conocida en el siglo XVI como estacamiento. Es decir, la señalización, mediante estacas de madera, de los límites de cada propiedad minera o veta, la cual era siempre proyectada por medio de rectángulos. Todo minero que lograba formalmente el reconocimiento como primero descubridor estaba obligado a presentar sus estacas o límites a quien se lo solicitara $y$, en caso de ser renuente a dar estacas a los mineros solicitantes recién llegados, el alcalde mayor de la jurisdicción estaba a su vez obligado a proceder al acotamiento de la mina, «llevando consigo personas que las sepan estacar, juramentados».75

Si en el momento de la petición de estacas el primero descubridor no se encontrara en su mina pero sí en la comarca, estaba obligado a dar las estacas al día siguiente de que fuera formulada la petición. Si estuviera ausente de la comarca, el alcalde mayor procedería al acotamiento en los términos indicados. 


\subsection{Atribuciones del alcalde mayor en materia de mejoras de minas y de con- trol de la explotación}

Los peticionarios de minas tendrían la obligación de ahondar en tres estados por lo menos una de las catas que tuvieran en su veta, para lo que se les otorgaba un plazo de cuatro meses subsecuentes a la fecha de registro; en caso de incumplimiento perdería la propiedad, la cual pasaría al denunciador del incumplimiento de la regla, «y el juez que lo meta luego en posesión al tal denunciador con el mismo cargo de la ahondar, sin embargo de ninguna apelación». ${ }^{76}$

Otra acción en materia de propiedad y explotación minera en la que el alcalde mayor de Zacatecas tenía especial encargo era la llamada mejora de la mina, la cual consistía en la posibilidad de cambiar la orientación del rectángulo que delimitaba la mina con la finalidad de aprovechar las vetas en mejores condiciones. En ocasiones -cuando el trazado original colindaba con otra mina-, era posible mejorarla respetando las estacas concedidas al vecino. Cualquier minero que, habiendo dado estacas por alguno de los lados de su mina -0 estando dándolas-, alguien llegara a pedirle estacas por el otro lado de la mina; el minero a quien se pedían estacas conservaría el derecho a mejorar su mina antes de conceder estacas a los recién llegados, es decir, se le reconocía el derecho a cambiar la orientación de su rectángulo, a condición de que la operación fuese «sin perjuicio de las estacas que tiene dadas al primero que se las pidió...»"

La mejora era motivo de un procedimiento en el que los alcaldes mayores jugaban un papel primordial. El minero podía así incluir otras catas que hubiese hecho recientemente fuera de su traza original. El procedimiento indicaba que el interesado debía acudir ante el alcalde mayor para manifestar sus nuevas estacas, reubicadas a consecuencia de la mejora; entonces el justicia admitiría la mejora evitando perjuicios a terceros, y la asentaría al margen del registro original de la mina en el libro respectivo, «señalando la cata que se hace por principal de su mina».77

El laboreo de las minas también fue objeto de las ordenanzas de la Marcha y de su correcta ejecución quedó encargado el alcalde mayor, a fin de evitar que los trabajos extractivos se convirtieran en motivo de disputa entre los mineros. Con el trabajo y desmonte de sus vetas, ni los señores de minas ni sus mineros expertos y demás trabajadores, podían «echar en mina ni en pertenencia ajena la tierra que sacare de la dicha su mina, so pena de cincuenta pesos». En caso contrario la parte afectada podía quejarse ante la justicia, y ésta actuaría en consecuencia disponiendo que fuera limpiada de tierra la mina del afectado, a costa del responsable, quien no tendría derecho a apelar.

Además, el minero afectado podía pedir directamente al alcalde mayor que le. amparara en su posesión, «de manera que contra su voluntad no le sea hecho agravio ni labre nadie por la dicha su mina».78

Otra de las atribuciones concedidas a los alcaldes mayores en esta misma materia era la de asumir la autorización a los mineros que pretendieran hacer laboreo o 
saqueo por mina ajena aún en ausencia del dueño; a tal efecto, se debía pedir a la justicia la licencia para la operación, so pena de cien pesos y perdimiento de cualquier derecho posterior para entrar y sacar material por la mina ajena.

Finalmente, Martínez de la Marcha encargó a los alcaldes mayores la protección de los indios trabajadores respecto del mal trato del que pudieran ser objeto por sus patrones, ya que declaró estar enterado de que «muchos de los señores de cuadrillas y sus mineros tratan mal a los que así acogen para su servicio, que no los pueden sufrir». Fundamentándose en ello, dispuso que los trabajadores objeto de mal trato podían acudir ante el alcalde mayor del lugar y, «una vez hecha la averiguación y encontrando ser verdad», que la justicia «le dé por quito del servicio y no sea obligado a servir»

\section{EL CORREGIMIENTO DE LA MUY NOBLE Y LEAL CIUDAD DE NUESTRA SEÑORA DE LOS ZACATECAS}

No podemos concluir este ensayo sin dar cuenta del otro importante oficio de justicia y gobernación que existió en Zacatecas durante el siglo XVI, a partir del 22 de mayo de 1580, previo a la concesión del título de ciudad, en 1585; se trata del Corregidor de la Ciudad Nuestra Señora de los Zacatecas 79 nombramiento del primer funcionario con este título en Zacatecas es más bien escueto si lo comparamos con el de los nombramientos que solía dar la audiencia a los alcaldes mayores que lo habían precedido hasta esa fecha. Y además hay que apuntar que en él se da por supuesta la existencia de un corregidor con anterioridad a la fecha de su expedición, y fundamenta en los usos y las costumbres del lugar, las atribuciones del nuevo corregidor.

Ateniéndonos al primer nombramiento de este género que se dio para Zacatecas, extendido a favor de don Félix de Zúñiga y Avellaneda, en 22 de mayo de 1580, 80 concluimos que tenía las siguientes facultades:

a) La administración de la justicia ordinaria en la jurisdicción de las minas en materia civil y criminal.

b) La de nombrar uno o varios tenientes en los términos de la jurisdicción, para el auxilio en sus funciones.

c) La facultad de portar vara de justicia.

El corregidor de Zacatecas debe distinguirse de los corregidores de los pueblos de indios. En primer lugar su designación provenía directamente del rey, quien lo escogía de entre un grupo de candidatos propuestos por el Consejo de Indias. Además debe destacarse que su salario era notoriamente mayor que el de los alcaldes mayores y corregidores de indios nombrados por la Audiencia de la Nueva Galicia; don Félix de Zúñiga percibía un salario de mil pesos de oro de minas al año, mientras los alcaldes mayores de Zacatecas ganaban, en 1570, 200 pesos de oro común. 
El corregidor de la ciudad de Zacatecas se proveía por el término de cinco años. Y la audiencia no podía tomarle, al vencimiento del ejercicio de aquél, el juicio de residencia, el cual era competencia de las autoridades metropolitanas, quienes además delegaban tal facultad en el nuevo corregidor. Asumía las obligaciones, libertades y preeminencias de sus predecesores los alcaldes mayores. El por qué de este cambio debemos encontrarlo en dos factores: en el empeño político de la oligarquía minera local por lograr para Zacatecas su condición de ciudad y, por otra parte, el interés de la Corona por ejercer un control más cercano y directo sobre uno de los enclaves mineros más importantes en sus dominios indianos. Con la real cédula que concedió el título de Noble y Leal Ciudad a Zacatecas, el rey procedió a dotarle de un juez-gobernador conforme a la idea de ennoblecimiento urbano que existía en la época. Al mismo tiempo se designó por primera vez en Zacatecas una figura auxiliar en la ejecución de la justicia del corregidor: el alguacil mayor.

En todo el territorio del virreinato de la Nueva España, en esa época, el rey sólo proveía tres corregimientos, el de la ciudad de México, el de Puebla y el de Zacatecas.

\section{NOTAS}

1 BAKEWELL, P.J. Minería y sociedad en el México colonial Zacatecas 1546-1700. Fondo de Cultura Económica. México. 1984. p. 17

2 República. Se usa aquí en el sentido de comunidad Política-cuerpo místicoorganizada mediante instituciones, tal y como se le utilizaba en la época de la fundación de Zacatecas.

3 HOYO DEL, Eugenio. «La diputación de mineros en las Minas Ricas de los Zacatecas. Democracia corporativa». Primer libro de actas de cabildo de las Minas de los Zacatecas. 1557-1586. H. Ayuntamiento Constitucional de Zacatecas. Zacatecas. 1991. p. 13.

4 Otro funcionario judicial de competencia local, lo serían, a partir de enero de 1587 los dos alcaldes ordinarios que se elegían anualmente en el cabildo de la ciudad, pero el objeto de este estudio sólo se enfoca a los alcaldes mayores y corregidores, es decir, a la justicia del rey.

5 GARCIA GALLO, Alfonso. «Alcaldes mayores y corregidores en Indias». En Estudios de Historia del derecho indiano. III Congreso del Instituto Internacional de Historia del Derecho Indiano. Madrid. 1972. p. 699.

6 SOLORZANO Y PEREYRA, Juan de. Política Indiana. Ediciones Atlas. Madrid. 1972. Tomo IV p. 24. Solórzano hace aquí un uso indiscriminado de los conceptos de Corregidor, Alcalde Mayor y Gobernador. Atribuye su origen al celo que la 
Corona española puso para «gobernar, defender y mantener en paz y justicia a los Españoles e Indios que las habitan, a imitación de lo que en los Reinos de Castilla y león hicieron los Reyes Católicos ( ... )» los magistrados a que se refiere, eran llamados Corregidores en el Perú, y Alcaldes Mayores en la Nueva España.

7 GARCIA GALLO, Alfonso. Op. Cit. p. 699.

8 Espéculo 4, 1. Citado por GARCIA GALLO, Alfonso. Op. Cit. p. 702.

9 PEREZ PRENDES, José Manuel et Al. Lecciones de Historia del Derecho Español. Centro de Estudios Ramón Areces. Madrid. 1992. pp. 227 y 228.

10 Juditio. Poder para juzgar.

11 lus Puniendi. El derecho de castigar.

12 Sobre el proceso de instauración del lus Puniendi en España, durante la transición de la Edad Media a la Moderna, así como la función que en él cumplió el Derecho Penal, véase TOMAS Y VALIENTE, Francisco. El Derecho Penal de la monarquía absoluta. (Siglos XVI, XVII y XVIII). Tecnós. Madrid. 1992.

13 GARCIA CALLO, Alfonso. Op. Cit. p. 707.

14 ldem. p. 709.

15 Los alcaldes ordinarios eran jueces elegidos por el cabildo de los ayuntamientos y tenían jurisdicción mixta sobre la ciudad o villa.

16 GARCIA GALLO, Alfonso. Op. Cit. p. 721

17 ldem. p. 730.

18 Idem. pp. 732 y 733

19 Citado por SCHÄFER, Ernst. El Consejo Real y Supremo de las indias, su historia, organización y labor administrativa hasta la terminación de la Casa de Austria. M. Carmona. Sevilla. 1945-1947. T 2. p. 271.

20 PARRY, J.H. The Audiencia of New Galicia in the sixteenth century. A study of Spanish Colonial Government. Cambridge University Press. Cambridge. 1968. pp. 14 y 15.

21 GERHARD, Peter. The North Frontier of New Spain. Princeton University Press. Princeton N.J. 1982. p. 90.

22 Idem. p. 118

23 SANCHEZ-ARCILLA, José. Ordenanzas de las Audiencias de Indias. Dykinson. Madrid. 1992. p. 141.

24 PARRY, J.H. Op. Cit. p. 41 
25 Delitos de Corte. Se conocían como tales, desde la Edad Media, aquellos delitos de singular gravedad, que debían ser juzgados y sentenciados por el rey o sus alcaldes de corte. Vid. TOMAS Y VALIENTE, Francisco. Op. Cit. p. 25.

26 Se trata de la llamada Audiencia de los Confines con jurisdicción en los actuales territorios de Guatemala y Nicaragua, creada en 1542

27 Vara de Justicia. Era la insignia y símbolo de la jurisdicción que portaban en la mano los magistrados y justicias. Tenía en su extremo superior una cruz, sobre la cual el juez pedía los "juramentos de derecho".

28 Esta facultad de los alcaldes mayores para fiscalizar las actividades de los funcionarios de la Real Hacienda se reconoció también tal cual a los corregidores que a partir de 1580 se nombraron por la Corona en Zacatecas. Cfr. ENCISO CONTRERAS, José. «Mercado de vino, mercaderes y fraude de la sisa en Zacatecas (1583-1584).» En Estudios de Historia Novohispana, volumen 14. Universidad Nacional Autónoma de México. México. 1994. pp. 9-37.

29 Audiencia Subalternada. Era aquella en la que no se nombraba un presidente encargado de la gobernación del territorio, ni tenía cancillería con el correspondiente sello real, por lo que no podía emitir mandamientos a nombre del rey. Además ciertas decisiones que de ella emanaban eran apelables ante otra audiencia superior.

30 Cfr. ENCISO CONTRERAS, José. «Las ordenanzas de la Audiencia de la Nueva Galicia». En la revista Quid Justitia. Poder Judicial del Estado de Zacatecas. Zacatecas. Número 1. junio de 1994. p. 19. «Hacia 1572 la audiencia fue reorganizada mediante otras ordenanzas que le concedieron el rango de cancillería real, no obstante retirarle cualquier competencia de gobernación que no fuese auxiliar.» Las ordenanzas que fueron vigentes para la Audiencia de la Nueva Galicia desde entonces fueron las llamadas Ordenanzas Generales de la Audiencia de Monzón, que ya se aplicaban en Quito y Charcas.

31 PARRY, H. Op. Cit. p. 121

32 Archivo General de Indias de Sevilla (AGI), en la sección Guadalajara, legajo número 5. (En adelante los documentos provenientes de este archivo se citarán de la siguiente manera: la sección, el número del legajo, el número del documento o el ramo en su caso, de tal forma que esta referencia quedaría: AGI, Guadalajara 5,). En las Averiguaciones hechas por el ilustre señor licenciado Contreras y Guevara, oidor y alcalde mayor de la Audiencia Mayor del Reino de la Nueva Galicia, y el más antiguo, sobre lo tocante a la visita del real Consejo de Indias. Fechadas en Guadalajara, el 10 de marzo de 1570 . Véase el testimonio del escribano Alonso Sánchez de Toledo sobre las ciudades, villas y poblaciones de la Nueva Galicia. Guadalajara, 22 de febrero de 1570.

33 PARRY, H.J- Op. Cit. p. 121 
$34 \mathrm{El}$ nombramiento de Antonio Maldonado a que se hace referencia, se encuentra en Archivo Histórico de Zacatecas.(AHZ) Libro Primero del Gobierno de esta Muy Noble y Leal Ciudad de Nuestra Señora de los Zacatecas, desde el año de mil quinientos y cincuenta y siete hasta el de mil quinientos y ochenta y seis. Folios 10, 10v, 11, 22, 44 y 44v. La minuta conteniendo el machote utilizado por la audiencia para el nombramiento de los corregidores, se encuentra en el AGI, Guadalajara 5, Averiguaciones... Guadalajara, el 10 de marzo de 1570.

35 Tamemes. Vocablo del náhuatl, que significa porteador o cargador.

36 Mezquituta. Era un pueblo de indios cuya ubicación se encuentra actualmente en el municipio zacatecano de Moyahua. Ver en el mapa anexo la provincia marcada con el número 15, correspondiente a Juchipila.

37 Las reales cédulas aquí citadas, donde se contienen los nombramientos referidos, se encuentran en $A H Z$ Libro Primero... Folios 10, 10v, 11, 22, 44 y $44 \mathrm{v}$.

38 Causas, delitos y penas arduas. Son equivalentes a los ya citados en el caso de los delitos de corte. Véase la nota 25.

39 OROZCO Y JIMENEZ, Francisco. Colección de Documentos Inéditos o muy raros referentes al Arzobispado de Guadalajara. (CODOIN). Tomo 1, No. 1 . Tipografía de Loreto y Ancira. Guadalajara. 1922. p. 99

40 HOYO, Eugenio del. Op. Cit. p. 13.

41 LOPEZ PORTILLO Y WEBER, José. La Conquista de la Nueva Galicia. Peña Colorada. México. 1980. p. 120.

42 AMAYA TOPETE, Jesús. Apéndice. Biblioteca de Occidente. Conquistadores y conquistas. Fundadores y fundaciones. Pobladores y poblazones. Incluso lo de Ameca. S. P. l. Guadalajara S.F.E. p. 53.

43 AGI, Guadalajara 34, 5. Los mineros y demás personas que tienen minas de plata en los Zacatecas, del Nuevo Reino de Galicia. Sobre que se les haga la gracia de que, como pagan en diezmo a su majestad, sea el veinteno, en atención a lo que componen. Zacatecas, 6 de febrero de 1558.

44 AGI, Guadalajara 33, 1. A su majestad, de los ofíciales de la Nueva Galicia. Zacatecas, 23 de septiembre de 1555.

45 MOTA PADILLA, Matías de la. Historia de la conquista de la provincia de la Nueva Galicia. Ediciones de México. Guadalajara. 1920. p. 139.

46 AGI, Guadalajara 33, 1. A su majestad, de los oficiales...

47 AGI, Contaduría 841. Cargo que se hace al tesorero don Rodrigo de Velasco, de las penas de cámara que se meten en la caja de su majestad, desde el primero de abril de mil quinientos y setenta y uno en adelante. Zacatecas, 17 de marzo de 1572 . 
48 AHZ, Libro Primero. Ffo.23v,25,26v y 35.

49 AMAYA TOPETE, Jesús. Op. Cit. . 41

50 Cfr. ACUÑA, René (editor). Relaciones geográficas de/ siglo XVI: México. Volumen 7, Tomo II. Universidad Nacional Autónoma de México. México. 1986. 107-112. Passim. « ... durante un tiempo residió en Zacatecas, y casó en México con doña Catalina Ortiz criada de doña Ana de Castilla, esposa del virrey don Luis de Velasco el viejo. Fue alcalde ordinario de la ciudad de México en 1570, junto con Leonel de Cervantes, hojo del comendador del mismo nombre, y, simultáneamente, entre 1580 y 1581, alcalde mayor de Cuilapa y de Iztepec... ». En una de sus cartas al rey en 1563 afirmó que «... habiendo veinte y seis años que sirvo a vuestra majestad en las conquistas y pacificaciones destas partes...», por lo que podemos inferir el año de su llegada a la Nueva España. El autor afirma que "...debió ser un hombre honesto y, a juzgar por sus cartas, no exento de idealismo."

51 Cfr. Recopilación de Leyes de los Reynos de las Indias. Consejo de la Hispanidad. Madrid. 1943. En adelante esta fuente será citada simplemente como Recopilación, seguida del número de libro en romanos, el título y el número de ley en arábigos. De tal manera que esta cita seria indicada como Recopilación IV: 21: 1,2 y 3 .

52 Recopilación IV: $21: 1$

53 Recopilación IV: $21: 2$ y 3

54 Recopilación IV: 21:4

55 Sobre los orígenes, naturaleza y organización de la Diputación puede consultarse ENCISO CONTRERAS, José. «La diputación de minas en Zacatecas, en el siglo XVI.» En la revista Vínculo jurídico. Revista de la Facultad de Derecho de la Universidad Autónoma de Zacatecas. Nums. 11 y 12. Zacatecas. julio-diciembre de 1992. pp. 50-67. Muy por el contrario a lo que sugiere el nombre que se le ha dado, la diputación de minas nunca tuvo atribuciones en materia minera.

56 ldem. p. 55

57 BAKEWELL, P, Op. Cit. p. 120

58 AGI. Guadalajara 35, No. 12. Corregidor de los Zacatecas. Licenciado Juan Núñez, sobre que pide no se nombren alcaldes ordinarios en la ciudad de la Concepción de los Zacatecas. Zacatecas, 4 de mayo de 1587. la primera elección de los regidores y alcaldes ordinarios del cabildo municipal de la ciudad de Nuestra Señora de los Zacatecas se efectuó el 4 de enero de 1587, estando al efecto presentes el corregidor, don Félix de Zúñiga y Avellaneda, los oficiales reales Alonso Caballero y Fernando de Velasco; así como el alguacil mayor Hernando Briseño. Los diputados mineros presentes fueron los mineros Cristóbal de Zaldívar y Baltasar de Rivera. Como alcaldes ordinarios resultaron electos Antonio de Salas y Alonso Hernández Bachiller, ambos viejos mineros locales. 
Los primeros regidores del cabildo municipal de Zacatecas resultaron ser Alonso Sánchez, Mateo de Errio, Ruy García de Ortega, Francisco Trejo y Cristóbal de Argüello, uno de los decanos de la minería en Zacatecas. Nombraron como «procurador general de esta ciudad» al ya citado regidor Alonso Sánchez, y como mayordomo del cabildo a Francisco Ramírez. Como mayordomo de la iglesia mayor se designó en esa ocasión a Antonio López de Cepeda; como fiel de pesas y medidas a Gonzalo de Cabañas, y como escribano, a Alonso de Avila León. También designaron un alarife llamado Juan.

$59 \mathrm{AHZ}$, Libro primero del gobierno, $\mathrm{Ff}^{\circ} 52,67 \mathrm{v}$ y 70.

60 Idem. $F^{\circ} 48$ v. Véase también ENCISO CONTRERAS, José. «Mercado de vino... »pp. 11 y 12 .

61 ENCISO CONTRERAS, José. «La Diputación... »p. 60. Más tarde, en abierta disputa con el justicia por esta prerrogativa, la audiencia de Guadalajara medió en el conflicto designando al fiel ella misma en diciembre de 1575. Esto se corrobora con otros indicios, pues ya para 1587 Baltasar de Bañuelos y los testigos que presentó para su descargo en el juicio de residencia que se le instruyó, aseguraban que desde hacía muchos años el control de las carnicerías, por ejemplo, era designado no ya por el alcalde mayor, sino directamente por la audiencia de Guadalajara, con un salario de 200 pesos anuales. En 1580, la facultad para designar al fiel de las tornó a Zacatecas, pero como facultad reservada para el corregidor.

62 Idem. En marzo de 1575, por ejemplo, requisaron importantes cantidades de maíz escondidas con fines especulativos.

63 Idem. p. 61.

64 El licenciado Hernán Martínez de la Marcha fue uno de los primeros cuatro oidores -el decano de la Audiencia de la Nueva Galicia, desde el 21 de mayo de 1549. Emprendió su visita desde Compostela, el 3 de diciembre de ese mismo año; en abril de 1550 ya estaba en las Minas de los Zacatecas, donde redactó no sólo las ordenanzas de minería a que nos referimos, sino también otras sobre el trabajo indígena en las actividades extractivas. Su visita por el reino se prolongó hasta el mes de diciembre de 1550. Pueden verse a este respecto BAKEWEI-L, Peter. Op. Cit. pp. 35 y 36. Además puede consultarse a GARCIA-ABASOLO GONZALEZ, Antonio Francisco. Resultados de una visita a Nueva Galicia en 1576. Separata del Tomo XXXVI, del Anuario de Estudios Americanos. Escuela de Estudios Hispano Americanos. Sevilla. 1979. Y también ROMAN GUTIERREZ, José Francisco. Sociedad y evangelización en Nueva Galicia durante el siglo XVI. Universidad Autónoma de Zacatecas -El Colegio de Jalisco- INAH. Guadalajara. 1993. p. 69, 79 y ss. Las ordenanzas de Martínez de la Marcha fueron hechas dos meses después del llamado el «First American Minning Code», del virrey Antonio de Mendoza -también en 1550-, y contuvieron algunas diferencias significativas que nos revelan cierto grado de especificidad de las regiones jurisdiccionales 
coloniales, y el celo que desde el principio de la creación de la Audiencia de la Nueva Galicia, se puso en la conservación de su jurisdicción sobre el nuevo y vasto territorio neogallego.

65 Estas ordenanzas mineras de 1550, para la Nueva Galicia, por otra parte, son parte del proceso regulador de la minería que, a nivel provincial, se desató en las posesiones españolas de Ultramar durante el siglo XVI, con fundamento en la tradición iniciada por el emperador Carlos 1, desde 1526.

66 RAMOS, Demetrio. Minería y comercio interprovincial en Hispanoamérica (siglos XVI, XVII y XVIII): Universidad de Valladolid. Valladolid. 1970. pp 57-76. $\mathrm{El}$ autor hace un amplio repaso a las regulaciones mineras dadas en la temprana ocupación de las Antillas, Nueva España, el Perú y Chile, así como de las variantes que la tradición legislativa minera española sufrió en su adaptación a las condiciones concretas de las diversas regiones. De cualquier forma, no pude decirse que el recuento realizado en esta obra haya sido exhaustivo, puesto que las disposiciones provinciales y hasta locales en materia minera debieron tener una profusión de amplias proporciones, como el propio autor lo intuye. Por ejemplo, sólo en el caso de Zacatecas, Ramos cita exclusivamente ciertas ordenanzas mineras dadas por el oidor, doctor Gerónimo de Orozco, en 27 de noviembre de 1579, cuando en realidad tales ordenanzas se refieren a asuntos de Real Hacienda y, en cambio, desatiende la importante serie de ordenanzas dadas durante el siglo XVI para Zacatecas. El documento citado por Ramos contiene en realidad las Nuevas ordenanzas que el gobernador de la Nueva Galicia dio a los oficiales reales de ella, sobre el método que han de observar en la cobranza de la Real Hacienda. Guadalajara, 27 de noviembre de 1579, que se encuentra en AGI, Patronato Real, legajo 182 , ramo $53, n^{\circ} 8$.

67 La regulación de asuntos mineros para el caso de Zacatecas provinieron en gran parte de las ordenanzas redactadas con motivo de las visitas de los oidores. Hubo varias visitas a Zacatecas y obviamente varias ordenanzas más. Cfr. A.G.1. Guadalajara 5, r 12, $\mathrm{N}^{\circ}$ 21-23, $\mathrm{F}^{\circ}$ 122. Ordenanzas que hizo en las minas de los Zacatecas, el señor licenciado Francisco de Mendiola, oidor alcalde mayor de la Real Audiencia de este reino de Galicia. Zacatecas, 6 de marzo de 1578. E1 licenciado Mendiola anotó en el proemio de sus ordenanzas: "por cuanto de pedimento de los oficiales de su majestad, y de los diputados y algunos mineros de este real de minas de Zacatecas, de este reino, por mí fueron vistas las ordenanzas y provisiones y otros mandos dados por los señores de la Audiencia Real y por el licenciado de la Marcha, oidor y visitador que fue de él; y de los alcaldes mayores y jueces de residencia que aquí han sido..."

$68 \mathrm{AHZ}$ Libro primero, $\mathrm{Ff}^{\mathrm{D}} 15-15 \mathrm{v}$ 
69 En la jerga minera de la época, estaca era el trozo puntiagudo de madera que se utilizaba para señalizar los linderos y catas de una mina. Solía clavarse en los ángulos de la traza de la veta.

70 A.G.I. Guadalajara 5, r 12, N2 12-13.Ordenanzas de minas que hizo el licenciado Hernando Martínez de la Marcha, oidor alcalde mayor que fue de esta real audiencia de/ Nuevo Reino de Galicia, siendo visitador general de él. Zacatecas, 20 de abril de 1550 . $F^{\circ} 105$.

71 BAKEWELL, P. Op. Cit. p. 33. Según el autor, los tres estados equivalen a 5.5 metros.

72 A.G.I. Guadalajara 5, r 12, $\mathrm{N}^{\circ} 12-13$. Ordenanzas de minas que hizo el licenciado Hernando Martínez de la Marcha. Véanse sobre este procedimiento las ordenanzas VIII, IX, $X$ y XI.

73 Mil varas equivalen a 838 metros; con lo que se obtiene que los metales descubiertos debían estar en el centro de una circunferencia que tenía por diámetro 1,676 metros, y un área de $2.206 \mathrm{~km} 2$, o sea, 2,206,000 m2 en la cual no debía encontrarse descubierta mina alguna, con anterioridad.

74 Recopilación, IV: 19:1

75 A.G.I. Guadalajara 5, r 12, - $\mathrm{N}^{\circ} 12-13$. Ordenanzas de minas que hizo el licenciado Hernando Martínez de la Marcha- $\mathrm{F}^{\circ} 109$, ordenanza XVII.

76 Idem. F2 $109 \mathrm{~V}$, ordenanza XX

77 Idem. $\mathrm{F}^{\circ} 11 \mathrm{Ov}$, ordenanza XXVII.

78 Idem. $F^{\circ} 112 v$, ordenanza XLI.

79 Vale la pena señalar que el nombramiento del primer corregidor en Zacatecas por parte de la Corona, don Félix de Zúñiga, se dio en un contexto de contradicciones políticas de gran interés para quien desee investigar la sociedad zacatecana de la época. Véase al efecto ENCISO CONTRERAS, José. «Mercado de vino... » p. 25. «La llegada de Félix de Zúñíga, un sevillano que fue el primero de los corregidores de Zacatecas, nombrado directamente por la Corona, señaló el principio de esta inestabilidad política que marcó la vida en las minas durante la primera mitad de la década de los 80 del siglo XVI ( ... ) Las actividades del corregidor atentaban contra los mecanismos de funcionamiento burocrático y distribución de cuotas económicas en torno a Zacatecas...»

80 AGI, Guadalajara 230, libro $1 \mathrm{f}^{\circ}$. 359. Corregimiento de Zacatecas, Badajoz, 22 de mayo de 1580 . 